\title{
Correction to: The mysterious grooves of Volcán Bárcena: a review of the role of streamwise counter-rotating vortices during erosion by dilute pyroclastic density currents
}

\author{
Susan W. Kieffer ${ }^{1}$ (D) $\cdot$ Eckart Meiburg $^{2}$ (D) $\cdot$ Jim Best $^{3}$ (D) $\cdot$ Joanna Austin $^{4}$ (D)
}

Published online: 10 April 2021

(C) International Association of Volcanology \& Chemistry of the Earth's Interior 2021

Correction to: Bulletin of Volcanology (2021) 83: 26

https://doi.org/10.1007/s00445-021-01440-9

The original version of this article unfortunately contained a typographical error. In the original manuscript the age of Laacher See, Germany, was given as 110,000 B.P (Freundt and Schmincke, 1985). The age should have been stated as 11,000 B.P. This change does not affect the results or conclusions in the paper. (Subsequently, Bogaard (Earth Planet. Sci. Lett., 133, 166, 1995) dated the eruption at 12,900 B.P.).

The online version of the original article can be found at https:// doi.org/10.1007/s00445-021-01440-9

Susan W. Kieffer

s1kieffer@gmail.com

1 Department of Geology, University of Illinois, Urbana, IL 61801, USA

2 Department of Mechanical Engineering, University of California, Santa Barbara, CA 93106, USA

3 Departments of Geology, Geography and GIS, and Mechanical Science and Engineering and Ven Te Chow Hydrosystems Laboratory, University of Illinois, Urbana, IL 61801, USA

4 Department of Aerospace, GALCIT, California Institute of Technology, Pasadena, CA 91125, USA 